\title{
How does nature contribute to human mobility? A conceptual framework and qualitative analysis
}

\author{
Charlotte Wiederkehr $^{1}$, Matthias Schröter $^{1}, \underline{\text { Helen Adams }}^{2}$, Ralf Seppelt $^{1,3}$ and Kathleen Hermans ${ }^{1,4}$
}

\begin{abstract}
Different types of mobility are known as longstanding strategies used by humans to deal with environmental pressure. Immobility is relevant in this context as population groups may be at considerable risk but lacking the capacity or willingness to move. Despite significant advances in this research field, grasping especially the subjective dimension of people's migration decision remains challenging. Moreover, the conceptualization of cultural factors in this context has received rather marginal attention thus far. In light of this, we propose a framework that integrates the novel concept of nature's contributions to people (NCP) with migration theory, in particular the triad of migration need, ability, and aspiration. NCP goes beyond the popular notion of ecosystem services by conceiving nature-society relations in a more inclusive way with culture being a key element of these. Combined with migration need, ability, and aspiration, we argue that this approach offers a valuable nuanced perspective on nature-mobility interactions, including cultural aspects of natural resource use and varying degrees of agency related to mobility decision making. We apply the framework to two archetypal climate-related migration situations, southwestern coastal Bangladesh and the northern Ethiopian highlands, to delineate the diverse mechanisms through which environmental change shapes population movement in highly resource-dependent livelihoods. We show that based on the analyzed case studies most links can be drawn between material and regulating NCP and migration need, and that nonenvironmental factors play a crucial role in mediating nature's contributions to human mobility. More knowledge is needed though in particular on the influence of nonmaterial NCP on mobility decision making and on migration aspirations in general to better account for important cultural factors. We formulate a number of hypotheses and questions relevant for guiding future research that can inform policy interventions.
\end{abstract}

Key Words: Bangladesh; Ethiopia; immobility; mobility; nature's contributions to people; place attachment

\section{INTRODUCTION}

In light of global environmental change, in-depth knowledge is urgently needed on human immobility and, more specifically, on why people decide to remain in vulnerable places (Findlay 2012). Mobility is known to be a longstanding strategy used by households throughout the world to handle environmental stress and varying resource availability. Not moving is often considered as a societal norm, thus attracting less political and academic attention than migration (Zickgraf 2018). Yet, it is equally relevant in the context of environmental stress as population groups may be at considerable risk but unable to leave. So-called "trapped populations" are typically characterized by significant vulnerability resulting from a high level of poverty (and low adaptive capacity) combined with a high exposure to environmental risk (Foresight Report 2011, Black et al. 2013, Ayeb-Karlsson et al. 2018, Nawrotzki and DeWaard 2018). However, households might also decide to stay, for instance because of strong emotional ties to their area of origin, despite significant risks or possessing the resources to migrate (e.g., Artur and Hilhorst 2014, Adams and Kay 2019; see also Mortreux and Barnett 2017). Perceptions of environmental change and migration aspirations are highly subjective, and especially motivations to stay under unfavorable environmental conditions are not well explored yet (Jónsson 2011, Adams 2016). Despite a growing awareness of the relevance of immobility, a framework that explicitly considers both mobility and immobility, including varying degrees of agency, as possible and equally important outcomes including the contribution of environmental factors is still lacking.

The role of place-related cultural factors in migration decision making deserves more attention in general (e.g., Adger et al. 2013). Various authors have pointed at the potential for drawing more from the substantial migration literature and well-established concepts of social theory to enhance the theoretical foundations of the research field of environmental migration (e.g., Piguet 2013, Hunter et al. 2014). For instance, concepts such as sense of place or behavioral approaches can serve to put an explicit emphasis on cultural and socio-psychological factors in migration decision making, but are excluded from migration theories that tend to dominate in the environmental migration field, e.g., the gravity model, neo-classical economic models, the new economics of labor migration and sustainable livelihood approach (see also Fresque-Baxter and Armitage 2012, Adams and Adger 2013, Martin et al. 2014).

The notion of nature's contributions to people (NCP) has recently been coined by the Intergovernmental Science-Policy Platform on Biodiversity and Ecosystems (IPBES) and strives to approach nature-society-interactions in a more holistic way than, for instance, the well-known ecosystem service concept (Díaz et al. 2018). NCP explicitly refers to different knowledge and value systems and acknowledges the crucial role played by culture in

${ }^{1}$ Department of Computational Landscape Ecology, Helmholtz Centre for Environmental Research - UFZ, Germany, ${ }^{2}$ Department of Geography, King's College London, UK, ${ }^{3}$ Institute of Geoscience \& Geography, Martin-Luther-University Halle-Wittenberg, Germany, ${ }^{4}$ Laboratory of GeoInformation Science and Remote Sensing, Wageningen University and Research, Wageningen, The Netherlands 
defining all nature-society-links instead of confining it to one subcategory. In this regard, NCP reflects a response to some common points of criticism of the ecosystem service approach (Chan et al. 2012, Schröter et al. 2014, Ellis et al. 2019, Kirchhoff 2019). For instance, the notion of nature as a "service" provider is rejected in different cultural contexts (Borie and Hulme 2015, Kohler et al. 2019). The NCP concept is built on the premise to capture a broad range of worldviews and values (Díaz et al. 2018, Kadykalo et al. 2019), potentially facilitating the analysis of multiple social relations (Ellis et al. 2019) that are of importance for environment-related migration.

In order to address the above mentioned gaps, we propose to conceptually integrate NCP with the triad of migration need, ability, and aspiration. The distinction between people's need, ability, and aspiration to migrate (based on Carling 2002 and Black and Collyer 2014) is a useful perspective on varying degrees of pressure and agency in the context of population movement. Thus, we argue that combining these concepts allows us to account for both cultural facets of natural resource use and the subjective dimension of migration decision making, and therewith move beyond existing works in this research field. Operationalizing agency as the sum of migration need, ability, and aspiration and, hence, along a continuum better reflects people's reality on the ground (Hunter 2005, Erdal and Oeppen 2018) and can take us one step further toward providing the scientific basis for appropriate policy measures in the field of migration and disaster management. We specifically assess how declining and lacking NCP contribute to migration need, ability, and aspiration at the individual level in highly resource-dependent livelihood contexts. While acknowledging the multicausal nature of migration and its embeddedness within larger societal processes, the purpose of this paper is to further disentangle the diverse environment-related mechanisms contributing to different mobility and immobility outcomes.

We provide a concise overview of recent theoretical approaches to immobility and identify entry points for further conceptual work. Subsequently, we introduce the conceptual framework based on NCP and our methodology. In order to substantiate the framework we apply it using literature-based evidence, drawn from the published literature on climate-related migration in southwestern coastal Bangladesh and the northern Ethiopian highlands. Our findings illustrate the broad spectrum of naturemobility-interactions and the crucial influence of nonenvironmental factors, above all related to socioeconomic inequalities. We conclude that declining material and regulating NCP contribute especially to increased migration need and also reduced migration ability, whereas evidence on the influence of nonmaterial NCP and the role of migration aspirations is relatively scarce. We argue that our framework has the potential to contribute to closing this gap when applied in future migration studies. In this paper we offer a novel perspective on the topic and define a research agenda by deriving hypotheses and questions on the NCP-mobility relationship.

\section{CONCEPTUAL APPROACHES TOWARD IMMOBILITY}

The Foresight Report (2011) presents a conceptual framework that outlines migration drivers at various levels, therewith highlighting the complex and multicausal nature of migration. In addition, the framework illustrates how environmental change can act as indirect migration driver by influencing other drivers. The report was seminal for highlighting that most people stay and that these populations require policy focus. However, although the report mentions the possibility of people choosing to stay under environmental change, this aspect is not discussed further whereas the risks and challenges related to trapped populations are emphasized. This observation also applies to Black et al. (2013) who propose a framework that distinguishes between three interrelated mobility outcomes (displacement, migration, immobility) under extreme weather events, depending on vulnerability before, exposure during, and recovery after the event. Based on reviewed evidence, the authors underline that both populations who move and who remain may become trapped and vulnerable in the context of extreme events.

Drawing on Bangladesh and Kiribati as examples of lowelevation coastal zones, Murphy (2015) suggests a socialecological-systems-based resilience framework to disentangle the climate change-mobility nexus. The framework comprises four resilience dimensions (personal, institutional, household, structural) that influence migration decision making and are subject to change as part of an adaptive cycle. The author exclusively states trapped populations as possible immobility outcome.

Although referring to the same theoretical basis as Black et al. (2013) and Murphy (2015), the model of migration as response to climate change by McLeman and Smit (2006) sheds a different light on immobility. In this model, "no out-migration" is included as potential outcome, not only in cases where, depending on capital endowments, migration is not viable (in analogy with trapped populations) but also where other adaptation options are preferred. This points to the fact that migration is just one out of a range of adaptation strategies, and that immobility is not inextricably linked to lacking resources and high vulnerability but may just as well result from a high capacity to adapt in situ.

Nawrotzki and DeWaard (2018) analyze different characteristics of places that shape populations' mobility potential under climate change by using a combination of climate and census data from Zambia. In line with earlier assumptions on trapped populations, the authors indicate the link between poverty and immobility under climate stress, but emphasize the influence of both population and place vulnerability (Nawrotzki and DeWaard 2018). In this context, the authors use the concept of the "holding power of places," which relates to place-based factors that presumably trap people.

Adams (2016) argues that trapped populations exist along a continuum and constitute just one type of immobility. Based on empirical data from the Peruvian highlands and behavioral migration theory, the author indicates that the concept of place attachment, and resulting residential (dis)satisfaction, can offer more explanatory power for why people choose to remain in times of environmental stress than merely resource barriers. Accordingly, it is crucial to also consider the role of noneconomic benefits in migration decision making (Adams and Adger 2013, Adams 2016). In a similar vein, Thompson (2017) argues in favor of a "geographical imaginations approach" toward migration decision making. Originating in cultural geography and defined as "the mental images we hold of different places and of the people living there" (Thompson 2017:79), "geographical imaginations" 
shed light on the influence of place and culture on migration decision making. Based on interview data from the UK and Philippines, the author shows how a holistic and cultural approach can help to better understand the motivations behind nonmigration. This more recent body of work has provided nuance to why people remain in location and illustrates that the consideration of sociocultural factors is indispensable, especially for a better understanding of the motives behind voluntary immobility.

\section{CONCEPTUAL FRAMEWORK ELEMENTS}

\section{Nature's contributions to people (NCP)}

Migration is known to be a significant livelihood strategy in response to changes in ecosystem service availability, stability, and access, or to prevent ecosystem service overexploitation (Black et al. 2011, Adger and Fortnam 2018). Not surprisingly, the ecosystem service concept has been employed by some environmental migration scholars to tackle the complex links between changing environmental conditions and human mobility. Renaud et al. (2011), for instance, propose a decision framework based on coupled social-ecological systems and ecosystem services, that offers a categorization of environmentally induced migrants; yet, immobility is not included. Adams and Adger (2013) use ecosystem services to discuss the contribution of environmental factors to place utility and their role in the migration decision-making process, indicating that environmental migration studies have been largely limited to provisioning ecosystem services. Beyond these applications, however, Adger and Fortnam (2018) highlight the lack of consistent and comprehensive conceptualizations of the links between environmental change, ecosystem services, and migration.

The framework proposed in this paper draws on the concept of nature's contributions to people (NCP) that has been developed as part of a conceptual framework by the Intergovernmental Science-Policy Platform on Biodiversity and Ecosystems (IPBES). NCP are defined as "all the contributions, both positive and negative, of living nature (diversity of organisms, ecosystems, and their associated ecological and evolutionary processes) to people's quality of life"(Díaz et al. 2018:270). These contributions are further subdivided into material ("substances, objects, or other material elements from nature that directly sustain people's physical existence and material assets" Díaz et al. 2018:271), nonmaterial ("nature's effects on subjective and psychological aspects underpinning people's quality of life, both individually and collectively" Díazet al. 2018:271), and regulating ("functional and structural aspects of organisms and ecosystems that modify environmental conditions experienced by people and/or regulate the generation of material and nonmaterial contributions" Díaz et al. 2018:271) contributions. IPBES distinguishes 18 reporting categories of NCP (for explanations of each category see Supplementary Material of Díaz et al. 2018), which we use as a basis for this paper (see also Appendix 1). The IPBES conceptual framework illustrates nature, the benefits that humans derive from nature, and a good quality of life as key components (Díaz et al. 2015a, Pascual et al. 2017). Furthermore, Díaz et al. (2018) suggest a "context-specific" perspective on NCP next to a "generalizing perspective." Whereas the generalizing perspective, as applied in this paper, focuses on systematic assessments according to defined reporting categories, the "context-specific perspective" allows for inclusions of indigenous and local knowledge, which could be applied to environmental migration work in the future.

The IPBES framework, and related key terms developed from it, can be understood as a "Rosetta Stone" (Díaz et al. 2015b) enabling to translate between different understandings of the value of nature in different cultural settings. We propose that this characteristic is of particular value for migration research across different cultures. Through this interdisciplinary translation function the NCP concept is also intended to include a range of disciplines from the social sciences and humanities (Díaz et al. 2018), which fits well with the interdisciplinary environmental migration community. Overall, we suggest that because of its inclusive approach and the stronger emphasis on culture, the NCP concept can help reveal highly relevant mechanisms, especially drivers of voluntary immobility, which are largely missing in current conceptualizations of environmental change and migration.

\section{Migration need, ability, and aspiration}

In conceptual terms, human mobility and immobility can be conceived as the outcome of the interplay between the need, the ability, and the aspiration to migrate (see also Ionesco et al. 2017). The distinction between wanting to migrate and actually migrating goes back to the link between intentions and behavior central to microlevel migration decision research (e.g., Wolpert 1965, Speare 1974, De Jong et al. 1985) and, in particular, Carling's aspiration/ability model (2002). While covering varying degrees and balances between choice and coercion, aspiration is here understood as "a conviction that migration is preferable to nonmigration" (Carling and Schewel 2018:946), which, depending on a person's abilities, may or may not result in migration. Adding the "need" to move "based on some well-founded fear of the consequences if movement does not take place" as proposed by Black and Collyer (2014:52) can provide a conceptually more clear-cut distinction of especially vulnerable groups and help us understand why some people move despite low migration aspirations.

In this paper, the triad of migration need, ability, and aspiration is operationalized as follows:

1. Migration need ("must migrate"): resulting from a person's vulnerability ${ }^{[1]}$

2. Migration ability ("can migrate"): a person's capacity to leave based on individual characteristics and resources

3. Migration aspiration ("want to migrate"): a person's motivation to leave based on risk perception, self-efficacy, and place attachment

While acknowledging the relevance of household-level decision making, we focus on the level of the individual as embedded in and influenced by household dynamics. We claim that connecting migration need, aspiration, and ability with NCP offers a valuable perspective on how a decrease in or lack of NCP can influence human mobility and immobility in various ways.

Although seemingly straightforward, migration ability is a complex indicator because it depends on multiple factors at different scales, such as national migration laws and regulations, available infrastructure, and personal and household 
characteristics including age, health, and educational background (e.g., Zickgraf 2018). Different kinds of capital, such as financial resources or social networks at destination regions, can influence people's ability to move directly or indirectly (Black and Collyer 2014, Tebboth et al. 2019). Furthermore, environmental change processes may simultaneously increase the need for migration and reduce people's ability to do so, the "immobilising effect" of environmental change described in the Foresight Report (2011).

Migration aspirations, in turn, may be strongly influenced by how people perceive their own capacities, i.e., what they think they are capable of (sometimes termed "self-efficacy"); those who believe they face high migration barriers or that they are able to adapt in situ may be less inclined to leave their land, for instance (Grothmann and Patt 2005). In addition, aspirations are shaped by people's subjective evaluation of environmental change and risk, which may, and in fact often does, deviate from objectively measured data (Grothmann and Patt 2005, Hunter 2005, Koubi et al. 2016). Beyond self-perceived adaptive capacity and risk perception, it is clear that aspirations are formed in line with social norms, values, and traditions (e.g., mobile vs. sedentary lifestyle, migration narratives, gender roles) and, thus, need to be assessed within the larger societal context (De Jong 2000, Hunter and David 2011, Martin et al. 2014).

The recognition that culture shapes all nature-society links, as exemplified by the NCP concept, is growing among scholars concerned with people's behavior under environmental change, counterbalancing a research paradigm that has prioritized objective and material dimensions of adaptive capacity and wellbeing (Stedman 1999, Adger et al. 2011, 2013). Here, we understand "culture" as "the symbols that express meaning, including beliefs, rituals, art and stories that create collective outlooks and behaviors, and from which strategies to respond to problems are devised and implemented" (Adger et al. 2013:112). This may entail both material and nonmaterial aspects, and is often associated with places that are given meaning by people (Escobar 2001).

Various concepts from place identity theory that describe humans' relationship with their environment have been proposed to better understand how people perceive risks and respond to environmental changes by bringing a more subjective sociocultural dimension into play (Fresque-Baxter and Armitage 2012, Devine-Wright 2013, Quinn et al. 2018). In this paper, we concentrate on the notion of place attachment, defined as the "emotional bonds which people develop with various places" (Lewicka 2011:219). De Dominics et al.(2015), for instance, found a weaker relationship between the perception of flood risk and coping action in the case of households that displayed strong place attachment in comparison to less place attached households. Cultural and place-based factors are often key to the aspirations to stay despite climate change impacts (e.g., McNamara and Gibson 2009, Mortreux and Barnett 2009, Nielsen and Reenberg 2010, Arnall 2014, Artur and Hilhorst 2014). Beyond this, Dandy et al. (2019) suggest that place attachment may also influence environment-related migration by triggering the decision to leave when (place-based) loss of contributions becomes unbearable, or by shaping people's choice of destination and postmigration experience.

\section{METHODS AND DATA}

This paper focuses on two regions, the southwestern coast of Bangladesh and the northern Ethiopian highlands, to test and substantiate the framework elements with concrete examples. These regions constitute archetypal examples of the climate change-migration nexus that are present in public discourse and imagination. In addition, their selection was motivated by data availability and the observation of various significant fast- and slow-onset hazards affecting local livelihoods as well as different migration processes. Using snowballing technique, we selected peer-reviewed literature on environment-related migration for both regions. Criteria for selection included sufficient detail to be assigned to at least one of the subcategories of NCP and migration need, ability, or aspiration through qualitative analysis. We identified 11 relevant case studies from the Bangladeshi coast and nine from Ethiopia (see Tables 1 and 2). We applied the novel framework as an analytical lens, meaning that the different elements were used as search categories for extracting relevant information and structuring the findings. Thereby, we assigned information on environmental stress to the different subcategories of NCP stated above and information that relates to or can be transferred to different aspects of the migration decision and outcomes to migration need, ability, and aspiration. Note that we interpreted different indications of declining or lacking NCP and that these could result from environmental stress, such as climatic changes, overuse and degradation of ecosystems resulting from management decisions, or pollution, for instance. In addition, we distinguished between "indicators" of migration need, ability, and aspiration as factors that can be linked with NCP and "moderators," i.e., factors mediating the relationship between NCP and migration need, ability, and aspiration but not directly linked to NCP (see also Appendix 1).

\section{CASE STUDY REGIONS}

\section{Rural dwellers on the southwestern coast of Bangladesh}

Bangladesh is typically characterized by high climatic variability as well as a particularly high exposure of the population at the coast to environmental risks such as cyclones and floods, aggravated by sea-level rise and the subsidence of the GangesMeghna-Brahmaputra delta (e.g., Call et al. 2017, Roy et al. 2017, Nicholls et al. 2018). The socioeconomic context is shaped by food insecurity, political instability, and poverty. Population density remains high and, despite an ongoing rural-urban migration trend, predominantly rural (e.g., Hossain et al. 2016). The population is primarily Muslim, with certain Hindudominated villages, particularly fishing villages (e.g., Mallick and Vogt 2012). Societal norms remain conservative, including traditional gender-based division of labor. Housing of those living in coastal villages tends to be structurally weak (e.g., Kartiki 2011, Akter and Mallick 2013). Landownership is highly concentrated. The majority of households are landless or functionally landless with insufficient land to support a livelihood. Although agriculture and open access natural resources, e.g., fishing, form a key part of the rural economy, not everyone is able to access their benefits (e.g., Adams et al. 2018). Fisheries and farming activities are constrained by, inter alia, limited market access and irrigation water availability as well as increasing salinization of water and soils (e.g., Nicholls et al. 2018). Shrimp farming, although capital-intensive, has become a 
Table 1. Selected case studies from coastal Bangladesh and the respective types of migration considered in each study.

\begin{tabular}{|c|c|}
\hline Reference & Types of migration considered \\
\hline Bernzen et al. (2019) & $\begin{array}{l}\text { Migration (defined as "any move from the household in which the person no longer ate meals at the household table, } \\
\text { including moves both within the same union and outside the union," p. } 6) \text {, including both domestic and international } \\
\text { moves and temporary ( } \leq 6 \text { months of absence) and permanent ( }>6 \text { months of absence) }\end{array}$ \\
\hline Call et al. (2017) & $\begin{array}{l}\text { Temporary migration (defined as "an absence from the MDSS study area by any individual for more than one month, } \\
\text { followed by a return to the study area by } 2003, \text {, p. 159) }\end{array}$ \\
\hline Islam and Herbeck (2013) & Permanent and seasonal migration \\
\hline Kartiki (2011) & Seasonal, temporary, and permanent migration \\
\hline Mallick and Vogt (2012) & $\begin{array}{l}\text { Rural-urban migration ("caused by natural hazards which involves both permanent and temporary moves in search of } \\
\text { employment and livelihoods as a factor of natural calamities," p. 219) }\end{array}$ \\
\hline Mallick (2019) & $\begin{array}{l}\text { Seasonal migration (refers to "those who migrate once or twice at a particular period of the year, usually when there is } \\
\text { no available employment in their native communities," p. 10) and circular migration (refers to "those who migrate } \\
\text { regularly to earn money so that their families can stay in their place of origin," p. 10), also temporary and permanent, } \\
\text { internal and international migration considered }\end{array}$ \\
\hline Martin et al. (2014) & $\begin{array}{l}\text { Different types of mobility and immobility ("The decision to migrate could mean different scales of movement across } \\
\text { time and space, and not to migrate could mean choosing to do so, or being unable to move or, to put it bluntly, being } \\
\text { 'trapped'," p. 92) }\end{array}$ \\
\hline Paul and Routray(2011) & Temporary and permanent migration \\
\hline Penning-Rowsell et al. (2013) & $\begin{array}{l}\text { Evacuation, temporary, seasonal and permanent migration (..These movements may have been either permanent or } \\
\text { temporary, very localised or over relatively longer distances (e.g. } 200 \mathrm{~km}), " \text { p. } 1)\end{array}$ \\
\hline Rabbani et al. (2013) & Temporary and permanent (within the home district, to another nearby district or the capital) \\
\hline Saha (2017) & $\begin{array}{l}\text { Postcyclone rural-urban migration by entire households; also seasonal migration, internal and international migration } \\
\text { to India }\end{array}$ \\
\hline
\end{tabular}

particularly popular activity because of high economic returns and, as such, has expanded considerably. However, aquaculture has degraded coastal embankments, water quality, and wetland biodiversity (e.g., Kartiki 2011). Besides, some households have had to take on large amounts of debt to enter the industry. People residing near the Sundarban mangrove forest may also depend on forest resources for subsistence and income, e.g., honey and wax production, eco-tourism, and fuelwood extraction, in addition to protection from storm surges (e.g., Akter and Mallick 2013, Hossain et al. 2017). Medium-sized urban centers, e.g., Khulna, are growing rapidly leading to an expansion of periurban areas that can draw on both rural and urban modes of living and offer opportunities for livelihood diversification. Different forms of mobility already constitute an integral part of households' livelihood strategies (e.g., Afsar 2003). Temporary migration of family members to urban areas during the agricultural low season is common, which reduces the food burden on the household or generates remittances that enable relatives to remain in their area of origin (e.g., Mallick 2019).

\section{Rural subsistence farmers in the northern Ethiopian highlands}

The socioeconomic context of this region is shaped by population growth, food insecurity, and endemic rural poverty (Ezra and Kiros 2001, Bantider et al. 2011, Morrissey 2013). Environmental conditions are characterized by a rugged terrain with high differences in altitude producing various agro-ecological zones, as well as severe land degradation (Hermans-Neumann et al. 2017). Rainfall is bimodal with increasingly variable rainy seasons associated with recurrent drought risk (Rosell and Holmer 2007, Hermans and Garbe 2019). Livelihoods are predominantly based on mixed subsistence farming. Given limited water availability, dependence on rain-fed agriculture is high, making households particularly vulnerable to changes and fluctuations in the rainfall regime (e.g., Meze-Hausken 2000). Although women may participate in some agricultural activities, farming has traditionally been the male domain, whereas women are responsible for domestic activities (e.g., Gray and Mueller 2012). Female-headed households are on average worse off than maleheaded households in terms of land and livestock holdings and thus more vulnerable to economic and environmental shocks (e. g., Little et al. 2006, Mersha and Van Laerhoven 2016). Land scarcity is a major issue in this region (e.g., Asfaw et al. 2010). Because of small farm sizes and declining soil fertility, farm outputs are often insufficient to meet the needs of households and many are reliant on government food aid (e.g., Ezra 2001; USAID 2017, unpublished manuscript). These circumstances are reinforced by the rather insecure land tenure and the lack of possibility to acquire additional land (e.g., Ege 2017). Levels of formal education and livelihood diversification are generally low. Given the lack of infrastructure, credit facilities, and few off-farm employment opportunities in the area (e.g., Weldegebriel and Prowse 2017), farming households are rather isolated and tend to have no or few off-farm income sources and therewith limited risk-spreading possibilities. If available, remittances from household members who have engaged in labor migration can be a valuable complement of household assets (e.g., Little et al. 2006). Historically, there has been a general migration pattern from the degraded regions in northern Ethiopia to more fertile areas in the south and southwest, including resettlement programs initiated by the national government. More recently, international labor migration to Gulf countries has been increasing (Mersha and Van Laerhoven 2016).

\section{RESULTS}

\section{The Bangladesh case study region}

Indications of decreasing or lacking regulating NCP were found predominantly in reference to the occurrence of cyclones, tidal surges and flooding, riverbank and coastal erosion, and the salinization of soils and groundwater (e.g., Paul and Routray 
Table 2. Selected case studies from the Ethiopian highlands and the respective types of migration considered in each study.

\begin{tabular}{|c|c|}
\hline Reference & Types of migration considered \\
\hline Asfaw et al. (2010) & Seasonal labor migration, both rural-rural and rural-urban \\
\hline Bantider et al. (2011) & Permanent migration \\
\hline Gray and Mueller (2012) & $\begin{array}{l}\text { Distinction between moves within and outside the district and related to labor, marriage, or other reasons; migration } \\
\text { ("referring exclusively to long-distance moves," p. 144); mobility ("referring collectively to all changes of residence," p. } \\
\text { 144) }\end{array}$ \\
\hline Hermans and Garbe (2019) & $\begin{array}{l}\text { Permanent migration (defined as "migration of household members who left their household and had not yet returned } \\
\text { to their household at the time of the survey (and in most instances were highly unlikely to return as indicated by the } \\
\text { respondent)," p. 5), temporary migration (defined as "migration of household members who left their household at } \\
\text { least for a month, but ultimately came back to join their household again," p. 5), resettlement, directly drought-related } \\
\text { migration, opportunity seeking migration by young people, international migration to the Gulf States }\end{array}$ \\
\hline $\begin{array}{l}\text { Mersha and Van Laerhoven } \\
\text { (2016) }\end{array}$ & $\begin{array}{l}\text { Internal and international migration, temporary migration; mobility (defined as "the distribution of risk across } \\
\text { spaces," p. 1704) }\end{array}$ \\
\hline Meze-Hausken (2000) & Drought-induced migration; distress migration referring to specific emergency situations \\
\hline Morrissey (2013) & Rural-urban mobility \\
\hline Weldegebriel and Prowse (2017) & National and international migration, seasonal labor migration \\
\hline $\begin{array}{l}\text { Wondimagegnhu and Zeleke } \\
\text { (2017) }\end{array}$ & Rural out-migration, internal and international \\
\hline
\end{tabular}

2011, Penning-Rowsell et al. 2013, Bernzen et al. 2019, Mallick 2019; see Fig. 1). Changes in precipitation and temperature as well as drought and excess rainfall events (e.g., Call et al. 2017) are also mentioned, but figure less prominently. These extreme events and processes affect local livelihoods, inter alia by also impacting material NCP, by contributing to water stress (e.g., Kartiki 2011), loss of agricultural land (e.g., Islam and Herbeck 2013), crop failure and food insecurity (e.g., Rabbani et al. 2013), livestock fodder shortage and death (e.g., Saha 2017), reduced access and availability of mangrove resources (e.g., Martin et al. 2014), damaging of infrastructure, housing, etc. (e.g., Mallick and Vogt 2012), and health problems (e.g., Saha 2017).

Regarding indicators of people's migration need and ability, income is repeatedly emphasized as a major factor in migration decision making (e.g., Penning-Rowsell et al. 2013). A comparative study by Mallick (2019) illustrates the link between regulating and material NCP and migration need via the influence on agricultural income: those communities with lower exposure to extreme events and salinization also depend less on seasonal migration because of the favorable conditions for rain-fed rice production and associated labor opportunities. In general, wealthier households seem to face a lower migration need in situations of decreasing regulating and material NCP than poor households, and are ascribed a higher degree of flexibility and agency in the mobility decision making (Mallick and Vogt 2012, Call et al. 2017). In contrast, low-income groups with typically few resources to cope with environmental stress and recovery from shocks face an increased migration need and risk of being forced to leave (Mallick and Vogt 2012, Saha 2017) but simultaneously often lack the ability to do so (Kartiki 2011). In terms of mobility rates of different income groups, findings diverge, hence lending support to both the "environmental capital" and the "migration as last resort" thesis (e.g., Paul and Routray 2011). Beyond this, a recent study by Bernzen et al. (2019) found that individuals who are affected by cyclone-induced damage and not employed in the core agricultural and aquaculture sectors are more likely to migrate, suggesting a link between transferable assets, weaker rural ties, and higher flexibility and mobility.
Gender was found to be a key moderator in the case of both migration need and ability. Women are typically characterized as one of the most vulnerable groups because of gender inequalities and social norms (Penning-Rowsell et al. 2013, Martin et al. 2014), hinting at an enhanced migration need under decreasing or absent $\mathrm{NCP}$, including drought and flood events or water scarcity. However, it seems that the migration decision is usually taken by male household heads, and male household members tend to be the ones engaging in migration, whereas women rarely leave independently (Kartiki 2011, Mallick and Vogt 2012). Under certain circumstances, this can even increase both the vulnerability and immobility of women that are left with children in environmentally risky or degraded areas (Penning-Rowsell et al. 2013, Martin et al. 2014). Moreover, the impact of a reduction in NCP, such as decreasing soil fertility due to salinization, appears to be differentiated by both income and gender (Rabbani et al. 2013). Call et al. (2017), for instance, suggest that decreasing agricultural income reduces women's ability to migrate for education purposes or marriage but increases the probability of migration by men.

Another important factor mediating the link between changes in $\mathrm{NCP}$ and migration need and ability relates to location, meaning the physical exposure to hazards, the proximity to protection and access to infrastructure. For instance, households located in proximity to the coastline and rivers or in areas dominated by shrimp farming face higher cyclone-induced damage and arable land loss and were found to be more likely to migrate (Bernzen et al. 2019), whereas embankments, for instance, are associated with a lower migration need during flood events (Call et al. 2017). The remoteness of villages can constrain people's migration ability (Paul and Routray 2011), but does not necessarily result in reduced overall mobility if migration need remains high. In a multisite study by Rabbani et al. (2013), migration in the context of hazards was in fact highest in the most remote village characterized by higher poverty and lower education levels, less infrastructure, and lower accessibility of up-to-date information than other study sites. Under these circumstances, in situ adaptation measures were much less common than other strategies, including temporary and permanent migration (Rabbani et al. 2013). 
Fig. 1. Links between nature's contributions to people (NCP) and migration need, ability, and aspirations in southwestern coastal Bangladesh. Arrows drawn between these elements represent indications of connections found in the reviewed studies with bold arrows referring to particularly common and explicit connections, yet, are not to be understood as illustrating direct or monocausal linkages.

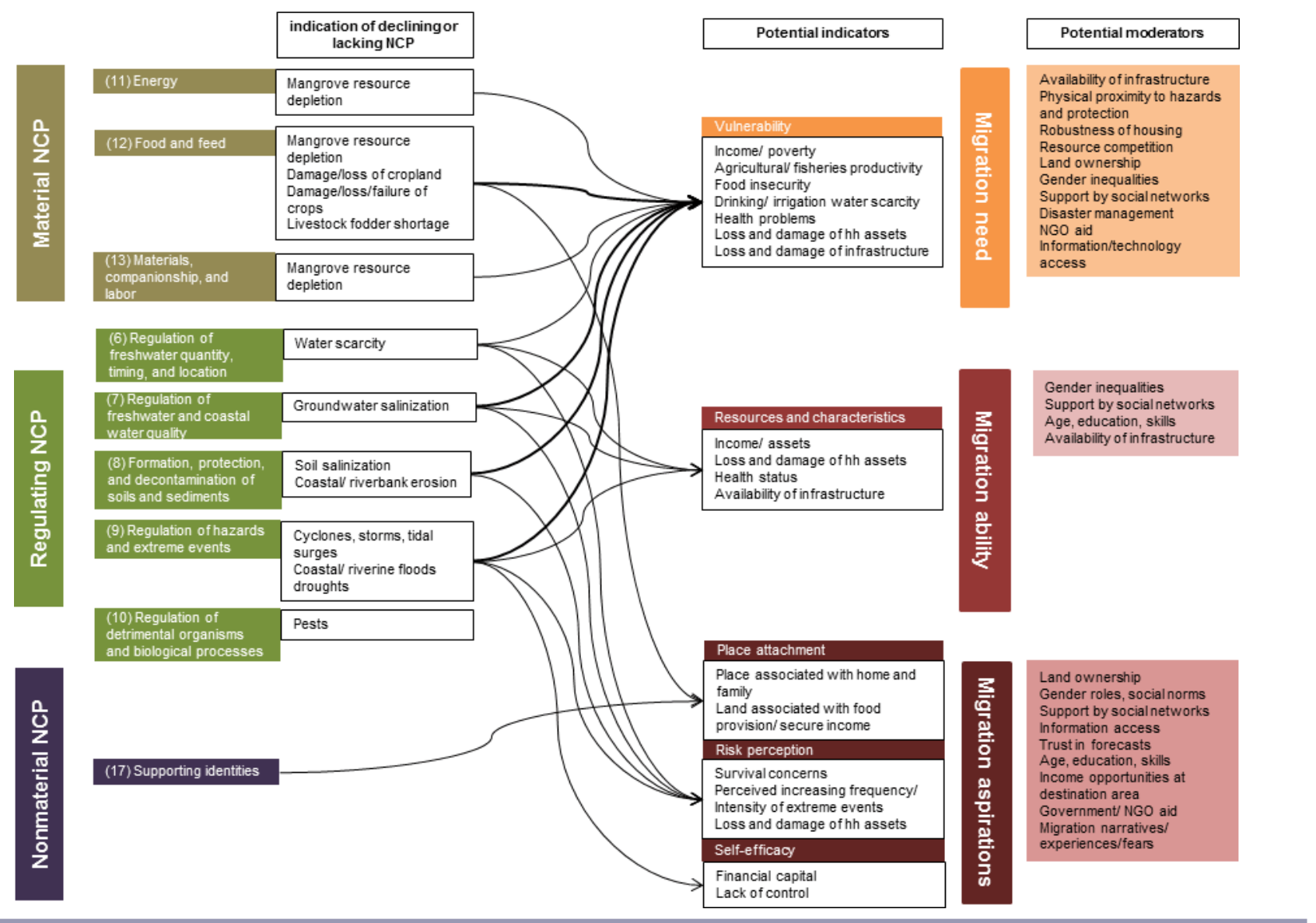

A diverse range of moderators influencing migration aspirations are reported in the reviewed studies from Bangladesh. The availability of support from social networks, prior knowledge about the destination area and (positively connoted) migration experiences, and narratives contribute, amongst others, to people's motivation to migrate (e.g., Kartiki 2011, Mallick and Vogt 2012, Martin et al. 2014). In addition, adverse working conditions at the area of origin or job opportunities in urban areas can enhance the incentive to favor mobility over rural livelihoods (e.g., Islam and Herbeck 2013). On the other hand, problems and risks associated with migration, such as health problems resulting from physical labor and poor living conditions in urban slums, or concerns among women regarding space and hygiene in cyclone shelters, discourage people from moving elsewhere (Paul and Routray 2011, Penning-Rowsell et al. 2013). The prospect of humanitarian aid or local support by affluent households may act as an additional disincentive for poorer groups despite, for example, cyclone-induced risks (Mallick and Vogt 2012). Furthermore, the lack of information, social networks, or financial capital can hinder people from even considering migration as an option because of costs (e.g., Kartiki 2011, Mallick 2019), which we interpret as low self-efficacy.
Beyond this, distrust in weather forecasts such as cyclone warnings due to negative experiences with false warnings in the past can bias people's risk perception and induce some not to evacuate despite declining regulating and material NCP (Mallick and Vogt 2012).

There are a few observations that may be interpreted as indications of place attachment. Both the studies of Kartiki (2011) and Islam and Herbeck (2013) address the common wish expressed among migrants to return home. Penning-Rowsell et al. (2013) mention strong "anchoring factors," including landholdings and houses, which motivate people to stay put despite decreasing material or regulating NCP, e.g., involving food shortages or storm surges. Other factors reducing migration aspirations include the closeness to family and home and perceived advantages of rural livelihood activities (such as income and food security associated with fishing or agriculture), which can be linked to material and especially nonmaterial NCP ("supporting identities"; e.g., Islam and Herbeck 2013). Importantly, land access and ownership seem to play a mediating role in this context; the lack of landholdings has been found to be positively associated with migration aspirations because 
Fig. 2. Links between nature's contributions to people (NCP) and migration need, ability, and aspirations in the northern Ethiopian highlands. Arrows drawn between these elements represent indications of connections found in the reviewed studies with bold arrows referring to particularly common and explicit connections, yet, are not to be understood as illustrating direct or monocausal linkages.

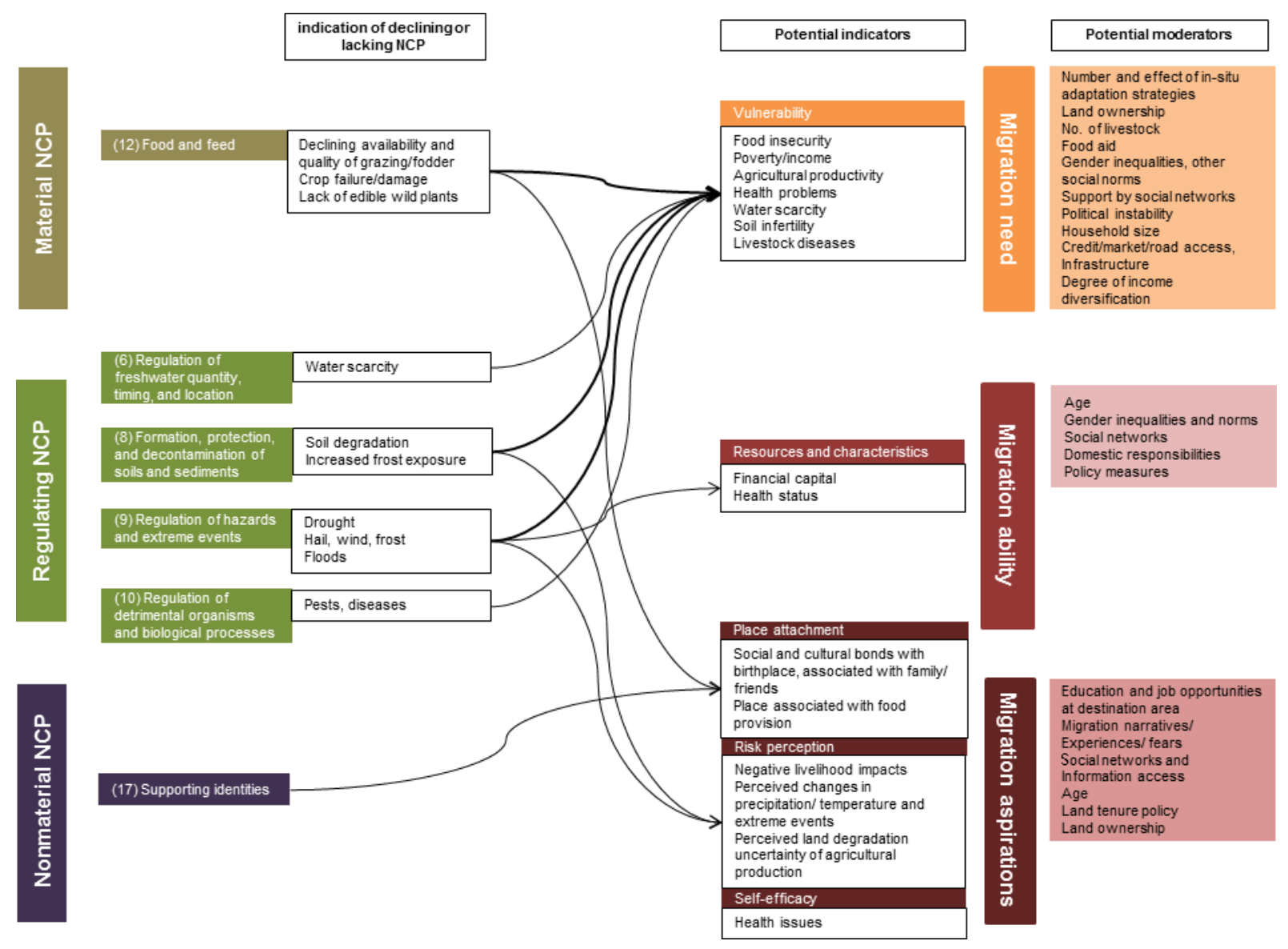

landless households lack the incentive to remain, for instance, in the form of ancestral property or farmland as reliable source of food provision (e.g., Kartiki 2011).

\section{The Ethiopia case study region}

The reviewed studies from Ethiopia mainly focus on changes in temperature and precipitation and in particular drought events (e.g., Gray and Mueller 2012, Wondimagegnhu and Zeleke 2017). Flood events and other idiosyncratic shocks, such as frost, pests, wind, and hail, are reported to a lesser extent (e.g., Morrissey 2013, Weldegebriel and Prowse 2017). In addition, water scarcity and soil degradation processes are common phenomena in this region, also hinting at decreasing regulating NCP (e.g., Bantider et al. 2011). Indications of declining or absent material NCP can be found regarding "food and feed" in terms of crop damage or failure, declining availability and quality of livestock feed, and lacking edible wild plants (e.g., Meze-Hausken 2000). These shocks and processes impact livelihoods mainly by contributing to food insecurity, health problems, and decreasing agricultural productivity and income (e.g., Hermans and Garbe 2019), which play an essential role for migration need, ability, and aspiration (see Fig. 2).
The Ethiopian case studies comprise a diverse range of moderators shaping people's migration need and ability under declining or absent material and regulating NCP. Amongst others, access to land, microcredit and especially food aid are cited as factors alleviating the "imperative to move" (e.g., Morrissey 2013, Weldegebriel and Prowse 2017). Information access and support by social networks are reported both as factors facilitating mobility and reducing vulnerability (e.g., Meze-Hausken 2000, Asfaw et al. 2010, Wondimagegnhu and Zeleke 2017). Furthermore, some studies hint at a positive association between the number of coping strategies employed by households (as well as a higher degree of income diversification in general) and their level of agency because diversification reduces migration need and the risk of "distress migration" (e.g., Meze-Hausken 2000). Beyond this, Hermans and Garbe (2019) illustrate the antagonistic effect of declining regulating and material NCP on migration need and ability by showing how drought exacerbates local poverty through food shortages and decreasing wealth while constraining people's ability to afford the costs of long-distance migration. Another hindering factor in this context was poor health, which is an important indicator of migration ability 
influenced by declining material and regulating NCP, such as regulation of freshwater quantity and quality or the provision of food and feed (Hermans and Garbe 2019).

Gender clearly mediates the influence of changing NCP on migration need and ability. Gray and Mueller (2012), for instance, found a decrease in short-distance and marriage-related migration by women in the context of drought because of their reduced ability to finance wedding expenses and new household formation, reflecting a lower migration ability. Mersha and Van Laerhoven (2016) underline the significant role of "gendered institutions" in both increasing women's vulnerability but simultaneously reducing their ability to adapt in-situ and migrate in the face of declining regulating and material NCP. This corresponds to observations by Asfaw et al. (2010) who relate the higher rate of seasonal labor mobility of men inter alia to their lower level of domestic responsibilities in comparison to women. Yet, it appears that no general conclusions can be drawn on gender-based differences in mobility because there is also empirical evidence indicating opposite tendencies (e.g., Wondimagegnhu and Zeleke 2017).

In line with the observations from Bangladesh, a variety of (both environmental and nonenvironmental) factors shape migration aspirations. Especially land ownership (or the lack thereof) is an important moderator in this regard (e.g., Morrissey 2013); in a study by Asfaw et al. (2010) land scarcity was cited by almost $80 \%$ of the migrants interviewed as the main reason for mobility. Furthermore, a range of socioeconomic motives, including food insecurity (related to declining material NCP), lack of income opportunities, and access to education contribute to increasing aspirations (e.g., Morrissey 2013, Hermans and Garbe 2019). Perception by locals of enhanced livelihood risks and impacts resulting from decreasing material or regulating NCP (e.g., Weldegebriel and Prowse 2017) is likely to enhance their motivation to employ mobility strategies.

Reported factors serving as disincentives include fears and low expectations associated with moving (Morrissey 2013, Hermans and Garbe 2019), but also certain government policies, for instance, regarding land tenure (migration resulting in a loss of landholdings) and ethnic-based population management (hampering inter-regional migration; Bantider et al. 2011). Further, the better off a household, the more likely it is that mobility can be used for accumulating assets and improving the household's living conditions, therewith contributing to positive migration narratives (Asfaw et al. 2010, Hermans and Garbe 2019). Indications of place attachment can be found in the reviewed studies above all in terms of cultural and social bonds with one's birthplace, which we interpret as "supporting identities" (nonmaterial NCP), that induce some people to stay put or to return to their area of origin (Bantider et al. 2011, Morrissey 2013, Hermans and Garbe 2019). Similar to the findings from Bangladesh, some respondents also associate their farmland with secure food provision for their family, which hints at a positive link between material NCP and place attachment (Hermans and Garbe 2019).

\section{DISCUSSION}

Two important observations can be made from the above analysis. First, most of the information available from the analyzed literature concerns agricultural productivity, food and water provision, and health, that is to say the interactions between material and regulating NCP and migration need. There is some evidence of "supporting identities," which, according to Díaz et al. 2018, may also involve "sense of place," contributing to people's place attachment and, hence, lower migration aspirations. In general, however, information on nonmaterial NCP ("learning and inspiration," "physical and psychological experiences," "supporting identities"), and how a decrease or lack thereof influences migration decision making, is scarce. Second, despite our focus on environment-related factors, the decisive role of what we call "moderators" cannot be overstated in this context. Especially factors such as gender or landownership that determine resource access and distribution and reflect multiple dimensions of inequalities among the study populations significantly shape the influence of changing NCP on migration decision making. This is in line with earlier claims of de Haas (2010), Black et al. (2011), Renaud et al. (2011), and Oliver-Smith (2012), amongst others. The consideration of these factors is thus indispensable for a holistic perspective.

For moving beyond an illustration of the mere linkages between declining or lacking NCP and migration need, ability, and aspiration and taking this discussion one step further, we derived hypothesized potential "directions" of these linkages at an aggregate level and illustrate those in Figure 3. Unlike the previous graphs, this is not exclusively based on literature from the two case study regions, but also draws from other insights of the research field.

Declining material and regulating NCP are generally associated with increasing migration need by adversely impacting livelihoods (Fig. 3, graphs 1 and 2). Importantly, some of the analyzed studies hint at a threshold at which people's coping or adaptive capacity is exceeded (indicated by a dotted line in graphs 1 and 2), meaning that basic survival needs can no longer be fulfilled and other options for action disappear (e.g., MezeHausken 2000, Paul and Routray 2011). Under such circumstances, migration, although not the preferred option, becomes the last resort (e.g., Mallick and Vogt 2012, PenningRowsell et al. 2013, Saha 2017). Thus, we assume that the greater the lack of material and regulating NCP (and therewith the pressure on livelihoods), the lower the degree of agency in the decision-making process (and the higher the risk of forced migration). The analyzed literature shows that a high level of NCP availability is often linked to higher migration ability, and declining material and regulating NCP tend to be associated with decreasing migration ability (Fig. 3, graphs 4 and 5), e.g., due to decreasing financial resources (e.g., Gray and Mueller 2012, Hermans and Garbe 2019). Therefore, we propose that the greater the lack of material and regulating NCP, the higher the probability of people getting trapped in risky places because of lacking migration abilities. The significance of agency and abilities in this context is corroborated by Tebboth et al. (2019) who found higher resilience levels among people who are able to choose and subsequently enact decisions about migration than others who are not. Graphs 3 and 6 in Figure 3 are left blank given the lack of evidence on the relationship between nonmaterial NCP and migration need and ability. 
Fig. 3. Hypothesized "direction" of the linkages between nature's contributions to people (NCP)/capita and migration need, ability, and aspiration.
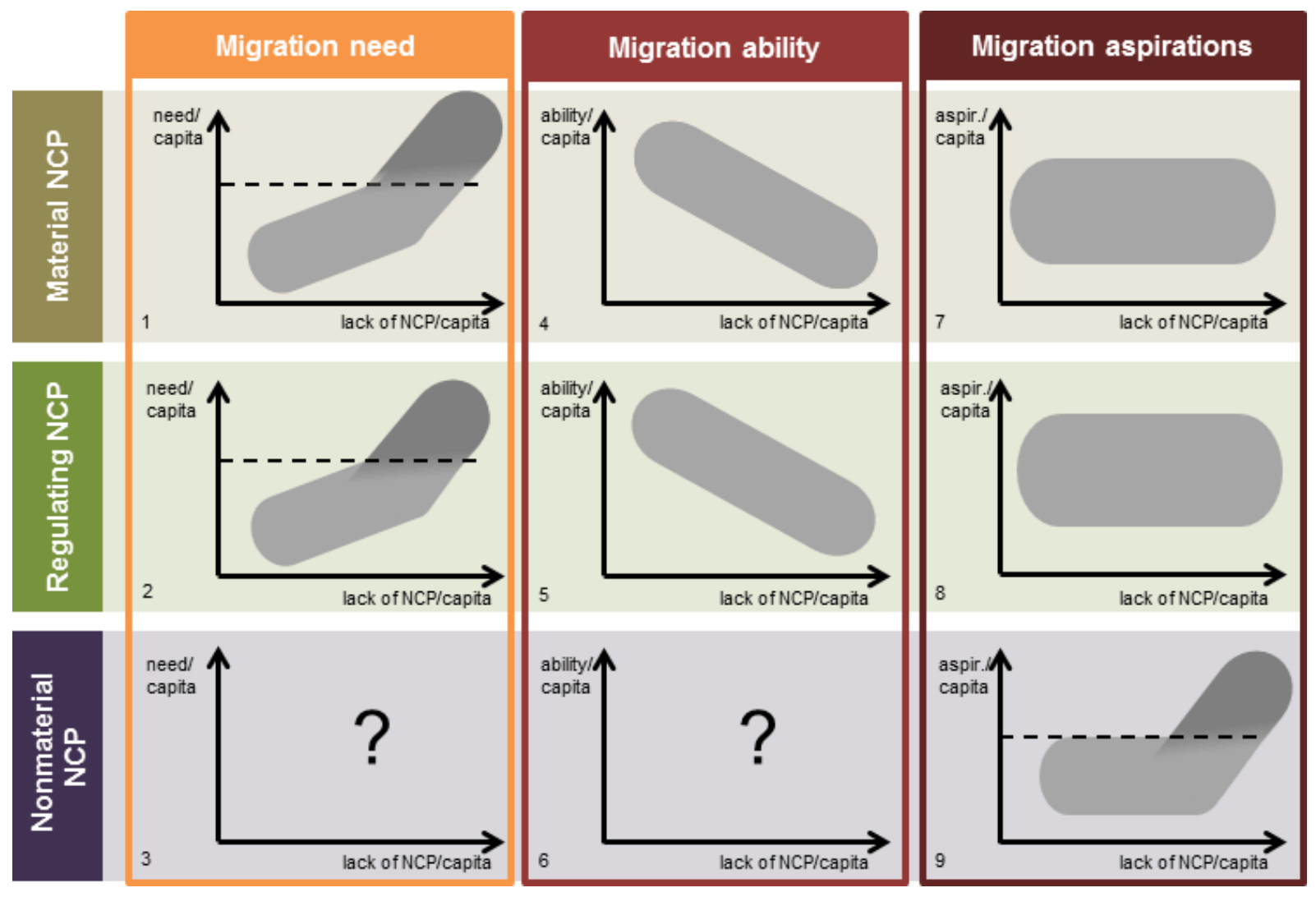

Box 1:

We identified the following as outstanding research questions to guide future field studies on the NCP-mobility relationship:

1. What are likely hotspots of involuntary mobility and immobility related to declining material and regulating NCP?

2. What are the most urgent policy measures required to enhance people's agency in migration decision making under declining material and regulating NCP?

3. How can potential thresholds of migration need and aspiration be determined and anticipated?

4. How does a decline in nonmaterial NCP influence migration need, ability, and aspiration?

5. How do NCP at destination areas influence people's migration decision?

6. How do specific moderators affect certain linkages between changes in NCP and migration need, ability, and aspiration?
In contrast to migration need and ability where the above illustrated tendencies are apparent, the picture is less clear-cut in the case of migration aspirations. Decreasing material or regulating NCP can provide sufficient incentives to increase people's migration aspirations, but not necessarily, as people may perceive environmental risks differently or think they are unable to move, i.e., low self-efficacy (Fig. 3, graphs 7 and 8). Moreover, strong place attachment related to nonmaterial NCP may also counterbalance incentives to leave. This is exemplified by case studies from Mozambique in which planned resettlement by the government due to high flood risk is opposed by many of the farmers who demonstrate a strong place attachment, in terms of traditional lifestyle, sacred sites, etc., and consider the risk less severe (Arnall 2014, Artur and Hillhorst 2014). Similarly, in a study by Mortreux and Barnett (2009) on Tuvalu, the majority of respondents prefer to stay for place attachment reasons despite sea level rise and the resulting migration need from an external perspective. Regarding the linkage between nonmaterial NCP and migration aspirations, Dandy et al. (2019) suggest a threshold at which the experienced contributions of a place that underpin place attachment are lost irreversibly, which induces people to move (indicated by a dotted line in graph 9, Fig. 3).

It needs to be underlined that our analysis has exclusively concentrated on the areas of origin, i.e., the "push factor" side of mobility processes. A consideration of NCP at respective destination areas and associated "pull factors" is surely relevant 
but beyond the scope of this study. Second, the findings presented here are essentially qualitative. The approach taken has been a first attempt to connect NCP with migration decision making and not deemed appropriate for quantifying identified linkages. Last, there are certain NCP types that are not addressed above because they were not found in the reviewed literature, but are nevertheless likely to play a role for natural resource-dependent livelihoods. These include inter alia pollination services, energy and materials, and the use of plants for medicinal purposes.

\section{CONCLUSION}

We here proposed a novel framework and made a first attempt to conceptualize the relations between material, regulating, and nonmaterial NCP and migration need, ability, and aspirations. Our aim was to enhance our understanding of environmentrelated mechanisms behind people's decision to migrate and to remain in location in contexts of environmental stress and highly resource-dependent livelihoods. A total of 20 case studies from the Bangladeshi coast and Ethiopian highlands have been analyzed qualitatively to substantiate our conceptual framework and explore remaining research gaps. Based on the assessed literature we have shown that the most links can be drawn between declining material and regulating NCP and migration need. There is also evidence hinting at links between nonmaterial NCP and migration aspirations; however, the scarcity of information on these means that cultural elements still remain a significant missing piece of the puzzle. Beyond this, the broad range of context-specific moderators that we encountered during the analysis underlines the important role of nonenvironmental factors in mediating the influence of changes in NCP on mobility decisions. This corroborates the complexity of causal relationships within migration processes and the need for continued efforts, above all on behalf of governments, to also address socioeconomic migration drivers resulting from persistent inequalities.

Whereas cautious propositions could be made on an aggregate level regarding the influence of changes in material and regulating NCP on migration need and ability, it is not yet possible to draw equally generic conclusions on declining nonmaterial NCP and migration aspirations in general because of too little evidence. The issue of aspirations deserves particular attention though because their consideration is indispensable to provide for ethically sound policy responses that avoid forcing people to relocate who wish to stay and prioritizing in situ adaptation that hinders those who want to leave. For a more complete picture of the topic, we thus strongly recommend further research on these aspects as well as potential thresholds of migration need and aspirations. In addition, there is a need to better understand how specific moderators affect specific pathways from changing NCP to mobility decisions to inform policy measures. Last, an examination of NCP at destination areas in addition to areas of origin could both enhance our understanding of environmentrelated pull factors and help decision makers identify immigration hotspots at risk of resource overexploitation.

Although it remains to be seen which linkages the framework reveals when being applied to other regional contexts, we trust that by highlighting certain subdimensions it will help to capture essential cultural aspects, such as place attachment, more systematically in future migration studies than before. In this regard, we believe that, in addition to the generalizing perspective applied here, the context-specific perspective on NCP could be particularly beneficial and should thus be explored in further research on the topic.

${ }^{[1]}$ Composed of risk exposure, sensitivity, and adaptive capacity (Adger 2006).

Responses to this article can be read online at: http://www.ecologyandsociety.org/issues/responses. php/11318

\section{Acknowledgments:}

$\mathrm{CW}$ and $\mathrm{KH}$ acknowledge funding from the German Federal Ministry of Education and Research (BMBF) within the Junior Research Group MigSoKo (01UU1606). The research reported in this paper contributes to the Programme on Ecosystem Change and Society (http://www.pecs-science.org/).

\section{LITERATURE CITED}

Adams, H., 2016. Why populations persist: mobility, place attachment and climate change. Population and Environment 37:429-448. https://doi.org/10.1007/s11111-015-0246-3

Adams, H., and W. N. Adger. 2013. The contribution of ecosystem services to place utility as a determinant of migration decisionmaking. Environmental Research Letters 8:015006. https://doi. org/10.1088/1748-9326/8/1/015006

Adams, H., W. N. Adger, and R. J. Nicholls. 2018. Ecosystem services linked to livelihoods and well-being in the GangesBrahmaputra-Meghna Delta. Pages 29-47 in R. J. Nicholls, C. W. Hutton, W. N. Adger, S. E. Hanson, M. Rahman, and M. Salehin, editors. Ecosystem services for well-being in deltas: integrated assessment for policy analysis. Palgrave Macmillan, Cham, Switzerland. https://doi.org/10.1007/978-3-319-71093-8 2

Adams, H., and S. Kay. 2019. Migration as a human affair: integrating individual stress thresholds into quantitative models of climate migration. Environmental Science \& Policy 93:129-138. https://doi.org/10.1016/j.envsci.2018.10.015

Adger, W. N. 2006. Vulnerability. Global Environmental Change 16:268-281. https://doi.org/10.1016/j.gloenvcha.2006.02.006

Adger, W. N., J. Barnett, K. Brown, N. Marshall, and K. O'Brien. 2013. Cultural dimensions of climate change impacts and adaptation. Nature Climate Change 3:112-117. https://doi. org/10.1038/nclimate1666

Adger, W. N., J. Barnett, F. S. Chapin III, and H. Ellemor. 2011. This must be the place: underrepresentation of identity and meaning in climate change decision-making. Global Environmental Politics 11:1-25. https://doi.org/10.1162/GLEP a 00051

Adger, W. N., and M. Fortnam. 2018. Interactions of migration and population dynamics with ecosystem services. Chapter 5 in K. Schreckenberg, G. Mace, and M. Poudyal, editors. Ecosystem 
services and poverty alleviation: trade-offs and governance. Routledge, London, UK. https://doi.org/10.4324/9780429507090

Afsar, R. 2003. Internal migration and the development nexus: the case of Bangladesh. Paper prepared for and presented at the Regional Conference on Migration, Development and Pro-Poor Policy Choices in Asia, 22-24 June 2003, Dhaka, Bangladesh. Refugee and Migratory Movements Research Unit, Bangladesh, and the Department for International Development, London, UK. [online] URL: https://pdfs.semanticscholar.org/ e65c/6a0ab60120841ac2fd2519e024cfed6beced.pdf? $\mathrm{ga}=2.251781578 .276354035 .1574859920-563038904.1574859920$

Akter, S., and B. Mallick. 2013. The poverty-vulnerabilityresilience nexus: evidence from Bangladesh. Ecological Economics 96:114-124. https://doi.org/10.1016/j.ecolecon.2013.10.008

Arnall, A. 2014. A climate of control: flooding, displacement and planned resettlement in the Lower Zambezi River valley, Mozambique: a climate of control. Geographical Journal 180:141-150. https://doi.org/10.1111/geoj.12036

Artur, L., and D. Hilhorst. 2014. Floods, resettlement and land access and use in the lower Zambezi, Mozambique. Land Use Policy 36:361-368. https://doi.org/10.1016/j.landusepol.2013.08.017

Asfaw, W., D. Tolossa, and G. Zeleke. 2010. Causes and impacts of seasonal migration on rural livelihoods: case studies from Amhara Region in Ethiopia. Norsk Geografisk Tidsskrift Norwegian Journal of Geography 64:58-70. https://doi. org/10.1080/00291950903557696

Ayeb-Karlsson, S., C. D. Smith, and D. Kniveton. 2018. A discursive review of the textual use of 'trapped' in environmental migration studies: the conceptual birth and troubled teenage years of trapped populations. Ambio 47:557-573. https://doi. org/10.1007/s13280-017-1007-6

Bantider, A., H. Hurni, and G. Zeleke. 2011. Responses of rural households to the impacts of population and land-use changes along the Eastern Escarpment of Wello, Ethiopia. Norsk Geografisk Tidsskrift - Norwegian Journal of Geography 65:42-53. https://doi.org/10.1080/00291951.2010.549954

Bernzen, A., J. Jenkins, and B. Braun. 2019. Climate changeinduced migration in coastal Bangladesh? A critical assessment of migration drivers in rural households under economic and environmental stress. Geosciences 9:51. https://doi.org/10.3390/ geosciences 9010051

Black, R., W. N. Adger, N. W. Arnell, S. Dercon, A. Geddes, and D. Thomas. 2011. The effect of environmental change on human migration. Global Environmental Change 21:S3-S11. https://doi. org/10.1016/j.gloenvcha.2011.10.001

Black, R., N. W. Arnell, W. N. Adger, D. Thomas, and A. Geddes. 2013. Migration, immobility and displacement outcomes following extreme events. Environmental Science \& Policy 27:S32S43. https://doi.org/10.1016/j.envsci.2012.09.001

Black, R., and M. Collyer. 2014. Populations 'trapped' at times of crisis. Crisis 5:52-56.

Borie, M., and M. Hulme. 2015. Framing global biodiversity: IPBES between mother earth and ecosystem services. Environmental Science \& Policy 54:487-496. https://doi. org/10.1016/j.envsci.2015.05.009
Call, M. A., C. Gray, M. Yunus, and M. Emch. 2017. Disruption, not displacement: environmental variability and temporary migration in Bangladesh. Global Environmental Change 46:157-165. https://doi.org/10.1016/j.gloenvcha.2017.08.008

Carling, J. 2002. Migration in the age of involuntary immobility: theoretical reflections and Cape Verdean experiences. Journal of Ethnic and Migration Studies 28:5-42. https://doi. org/10.1080/13691830120103912

Carling, J., and K. Schewel. 2018. Revisiting aspiration and ability in international migration. Journal of Ethnic and Migration Studies 44:945-963. https://doi.org/10.1080/1369183X.2017.1384146

Chan, K. M. A., A. D. Guerry, P. Balvanera, S. Klain, T. Satterfield, X. Basurto, A. Bostrom, R. Chuenpagdee, R. Gould, B. S. Halpern, N. Hannahs, J. Levine, B. Norton, M. Ruckelshaus, R. Russell, J. Tam, and U. Woodside. 2012. Where are cultural and social in ecosystem services? A framework for constructive engagement. BioScience 62:744-756. https://doi.org/10.1525/ bio.2012.62.8.7

Dandy, J., P. Horwitz, R. Campbell, D. Drake, and Z. Leviston. 2019. Leaving home: place attachment and decisions to move in the face of environmental change. Regional Environmental Change 19:615-620. https://doi.org/10.1007/s10113-019-01463-1

De Dominicis, S., F. Fornara, U. Ganucci Cancellieri, C. TwiggerRoss, and M. Bonaiuto. 2015. We are at risk, and so what? Place attachment, environmental risk perceptions and preventive coping behaviours. Journal of Environmental Psychology 43:66-78. https://doi.org/10.1016/j.jenvp.2015.05.010

de Haas, H. 2010. The internal dynamics of migration processes: a theoretical inquiry. Journal of Ethnic and Migration Studies 36:1587-1617. https://doi.org/10.1080/1369183X.2010.489361

De Jong, G. F. 2000. Expectations, gender, and norms in migration decision-making. Population Studies 54:307-319. https://doi. org/10.1080/713779089

De Jong, G. F., B. D. Root, R. W. Gardner, J. T. Fawcett, and R. G. Abad. 1985. Migration intentions and behavior: decision making in a rural Philippine province. Population and Environment 8:41-62. https://doi.org/10.1007/BF01263016

Devine-Wright, P. 2013. Think global, act local? The relevance of place attachments and place identities in a climate changed world. Global Environmental Change 23:61-69. https://doi.org/10.1016/j. gloenvcha.2012.08.003

Díaz, S., S. Demissew, J. Carabias, C. Joly, M. Lonsdale, N. Ash, A. Larigauderie, J. R. Adhikari, S. Arico, A. Báldi, A., Bartuska, I. A. Baste, A. Bilgin, E. Brondizio, K. M. A. Chan, V. E. Figueroa, A. Duraiappah, M. Fischer, R. Hill, T. Koetz, P. Leadley, P., Lyver, G. M. Mace, B. Martin-Lopez, M. Okumura, D. Pacheco, U. Pascual, E. S. Pérez, B. Reyers, E. Roth, O. Saito, R. J. Scholes, N. Sharma, H. Tallis, R. Thaman, R., Watson, T. Yahara, Z. A. Hamid, C. Akosim, Y. Al-Hafedh, R. Allahverdiyev, E. Amankwah, S. T. Asah, Z. Asfaw, G. Bartus, L. A. Brooks, J. Caillaux, G. Dalle, D. Darnaedi, A. Driver, G. Erpul, P. EscobarEyzaguirre, P., Failler, A. M. M. Fouda, B. Fu, H. Gundimeda, S. Hashimoto, F. Homer, S. Lavorel, G. Lichtenstein, W. A. Mala, W. Mandivenyi, P. Matczak, C. Mbizvo, M. Mehrdadi, J. P. Metzger, J. B. Mikissa, H. Moller, H. A. Mooney, P. Mumby, H. Nagendra, C. Nesshover, A. A. Oteng-Yeboah, G. Pataki, M. 
Roué, J. Rubis, M. Schultz, P. Smith, R. Sumaila, K. Takeuchi, S. Thomas, M. Verma, Y. Yeo-Chang, and D. Zlatanova. 2015a. The IPBES conceptual framework - connecting nature and people. Current Opinion in Environmental Sustainability 14:1-16. https:// doi.org/10.1016/j.cosust.2014.11.002

Díaz, S., S. Demissew, C. Joly, W. M. Lonsdale, and A. Larigauderie. 2015b. A Rosetta Stone for nature's benefits to people. PLOS Biology 13:e1002040. https://doi.org/10.1371/ journal.pbio. 1002040

Díaz, S., U. Pascual, M. Stenseke, B. Martín-López, R. T. Watson, Z. Molnár, R. Hill, K. M. A. Chan, I. A. Baste, K. A. Brauman, S. Polasky, A. Church, M. Lonsdale, A. Larigauderie, P. W. Leadley, A. P. E. van Oudenhoven, F. van der Plaat, M. Schröter, S. Lavorel, Y. Aumeeruddy-Thomas, E. Bukvareva, K. Davies, S. Demissew, G. Erpul, P. Failler, C. A. Guerra, C. L. Hewitt, H. Keune, S. Lindley, and Y. Shirayama. 2018. Assessing nature's contributions to people. Science 359:270-272. https://doi. org/10.1126/science.aap8826

Ege, S. 2017. Land tenure insecurity in post-certification Amhara, Ethiopia. Land Use Policy 64:56-63. https://doi.org/10.1016/j. landusepol.2017.02.015

Ellis, E. C., U. Pascual, and O. Mertz. 2019. Ecosystem services and nature's contribution to people: negotiating diverse values and trade-offs in land systems. Current Opinion in Environmental Sustainability 38:86-94. https://doi.org/10.1016/j.cosust.2019.05.001

Erdal, M. B., and C. Oeppen. 2018. Forced to leave? The discursive and analytical significance of describing migration as forced and voluntary. Journal of Ethnic and Migration Studies 44:981-998. https://doi.org/10.1080/1369183X.2017.1384149

Escobar, A. 2001. Culture sits in places: reflections on globalism and subaltern strategies of localization. Political Geography 20:139-174. https://doi.org/10.1016/S0962-6298(00)00064-0

Ezra, M. 2011. Demographic responses to environmental stress in the drought- and famine-prone areas of northern Ethiopia. International Journal of Population Geography 7(4):259-279. https://doi.org/10.1002/ijpg.226

Ezra, M., and G.-E. Kiros. 2001. Rural out-migration in the drought prone areas of Ethiopia: a multilevel analysis. International Migration Review 35:749-771. https://doi. org/10.1111/j.1747-7379.2001.tb00039.x

Findlay, A. M. 2012. Migration: flooding and the scale of migration. Nature Climate Change 2:401-402. https://doi. org/10.1038/nclimate1554

Foresight 2011. Migration and global environmental change: future challenges and opportunities. Final Project Report: Executive Summary. The Government Office for Science, London, UK. [online] URL: https://assets.publishing.service.gov.uk/government/ uploads/system/uploads/attachment_data/file/287717/11-1116-migrationand-global-environmental-change.pdf

Fresque-Baxter, J. A., and D. Armitage. 2012. Place identity and climate change adaptation: a synthesis and framework for understanding. Wiley Interdisciplinary Reviews: Climate Change 3:251-266. https://doi.org/10.1002/wcc. 164
Gray, C., and V. Mueller. 2012. Drought and population mobility in rural Ethiopia. World Development 40:134-145. https://doi. org/10.1016/j.worlddev.2011.05.023

Grothmann, T., and A. Patt. 2005. Adaptive capacity and human cognition: the process of individual adaptation to climate change. Global Environmental Change 15:199-213. https://doi.org/10.1016/ j.gloenvcha.2005.01.002

Hermans, K., and L. Garbe. 2019. Droughts, livelihoods, and human migration in northern Ethiopia. Regional Environmental Change 19:1101-1111. https://doi.org/10.1007/s10113-019-01473$\underline{z}$

Hermans-Neumann, K., J. Priess, and M. Herold. 2017. Human migration, climate variability, and land degradation: hotspots of socio-ecological pressure in Ethiopia. Regional Environmental Change 17:1479-1492. https://doi.org/10.1007/s10113-017-1108-6

Hossain, M. S., J. A. Dearing, M. M. Rahman, and M. Salehin. 2016. Recent changes in ecosystem services and human well-being in the Bangladesh coastal zone. Regional Environmental Change 16:429-443. https://doi.org/10.1007/s10113-014-0748-z

Hossain, M. S., F. Eigenbrod, F. A. Johnson, and J. A. Dearing. 2017. Unravelling the interrelationships between ecosystem services and human wellbeing in the Bangladesh delta. International Journal of Sustainable Development \& World Ecology 24:120-134. https://doi.org/10.1080/13504509.2016.1182087

Hossain, M. S., F. A. Johnson, J. A. Dearing, and F. Eigenbrod. 2016. Recent trends of human wellbeing in the Bangladesh delta. Environmental Development 17:21-32. https://doi.org/10.1016/j. envdev.2015.09.008

Hunter, L. M. 2005. Migration and environmental hazards. Population and Environment 26:273-302. https://doi.org/10.1007/ s11111-005-3343-X

Hunter, L. M., and E. David. 2011. Displacement, climate change and gender. Chapter 12 in E. Piguet, A. Pecoud, and P. de Guchteneire, editors. Migration and climate change. UNESCO Publishing and Cambridge University Press, Cambridge, UK.

Hunter, L. M., R. Nawrotzki, S. Leyk, G. J. Maclaurin, W. Twine, M. Collinson, and B. Erasmus. 2014. Rural outmigration, natural capital, and livelihoods in South Africa. Population, Space and Place 20:402-420. https://doi.org/10.1002/psp.1776

Ionesco, D., D. Mokhnacheva, and F. Gemenne. 2017. The atlas of environmental migration First edition. Routledge, London, UK.

Islam, M. M., and J. Herbeck. 2013. Migration and translocal livelihoods of coastal small-scale fishers in Bangladesh. Journal of Development Studies 49:832-845. https://doi.org/10.1080/002$\underline{20388.2013 .766719}$

Jónsson, G. 2011. Non-migrant, sedentary, immobile, or 'left behind'? IMI Working Paper Series No. 39:1-17. International Migration Institute, Oxford, UK.

Kadykalo, A. N., M. D. López-Rodriguez, J. Ainscough, N. Droste, H. Ryu, G. Ávila-Flores, S. L. Clec'h, M. C. Muñoz, L. Nilsson, S. Rana, P. Sarkar, K. J. Sevecke, and Z. V. Harmáčková. 
2019. Disentangling 'ecosystem services' and 'nature's contributions to people.' Ecosystems and People 15:269-287. https://doi.org/10.1080/26395916.2019.1669713

Kartiki, K. 2011. Climate change and migration: a case study from rural Bangladesh. Gender \& Development 19:23-38. https:// doi.org/10.1080/13552074.2011.554017

Kirchhoff, T. 2019. Abandoning the concept of cultural ecosystem services, or against natural-scientific imperialism. BioScience 69:220-227. https://doi.org/10.1093/biosci/biz007

Kohler, F., T. G. Holland, J. S. Kotiaho, M. Desrousseaux, and M. D. Potts. 2019. Embracing diverse worldviews to share planet Earth. Conservation Biology 33:1014-1022. https://doi.org/10.1111/ $\underline{\text { cobi. } 13304}$

Koubi, V., S. Stoll, and G. Spilker. 2016. Perceptions of environmental change and migration decisions. Climatic Change 138:439-451. https://doi.org/10.1007/s10584-016-1767-1

Lewicka, M. 2011. Place attachment: How far have we come in the last 40 years? Journal of Environmental Psychology 31:207-230. https://doi.org/10.1016/i.jenvp.2010.10.001

Little, P. D., M. P. Stone, T. Mogues, A. P. Castro, and W. Negatu. 2006. 'Moving in place': drought and poverty dynamics in South Wollo, Ethiopia. Journal of Development Studies 42:200-225. https://doi.org/10.1080/00220380500405287

Mallick, B. 2019. The Nexus between socio-ecological system, livelihood resilience, and migration decisions: empirical evidence from Bangladesh. Sustainability 11:3332. https://doi.org/10.3390/ $\underline{\text { su11123332 }}$

Mallick, B., and J. Vogt. 2012. Cyclone, coastal society and migration: empirical evidence from Bangladesh. International Development Planning Review 34:217-240. https://doi.org/10.3828/ idpr.2012.16

Martin, M., M. Billah, T. Siddiqui, C. Abrar, R. Black, and D. Kniveton. 2014. Climate-related migration in rural Bangladesh: a behavioural model. Population and Environment 36:85-110. https://doi.org/10.1007/s11111-014-0207-2

McLeman, R., and B. Smit. 2006. Migration as an adaptation to climate change. Climatic Change 76:31-53. https://doi. org/10.1007/s10584-005-9000-7

McNamara, K. E., and C. Gibson. 2009. 'We do not want to leave our land': Pacific ambassadors at the United Nations resist the category of 'climate refugees.' Geoforum 40:475-483. https://doi. org/10.1016/j.geoforum.2009.03.006

Mersha, A. A., and F. Van Laerhoven. 2016. A gender approach to understanding the differentiated impact of barriers to adaptation: responses to climate change in rural Ethiopia. Regional Environmental Change 16:1701-1713. https://doi. org/10.1007/s10113-015-0921-Z

Meze-Hausken, E. 2000. Migration causes by climate change: how vulnerable are people in dryland areas? Mitigation and Adaptation Strategies for Global Change 5:379-406. https://doi. org/10.1023/A:1026570529614

Morrissey, J. W. 2013. Understanding the relationship between environmental change and migration: the development of an effects framework based on the case of northern Ethiopia. Global Environmental Change 23:1501-1510. https://doi.org/10.1016/j. gloenvcha.2013.07.021

Mortreux, C., and J. Barnett. 2009. Climate change, migration and adaptation in Funafuti, Tuvalu. Global Environmental Change 19:105-112. https://doi.org/10.1016/i.gloenvcha.2008.09.006

Mortreux, C., and J. Barnett. 2017. Adaptive capacity: exploring the research frontier. Wiley Interdisciplinary Reviews: Climate Change 8:e467. https://doi.org/10.1002/wcc.467

Murphy, D. W. A. 2015. Theorizing climate change, (im)mobility and socio-ecological systems resilience in low-elevation coastal zones. Climate and Development 7:380-397. https://doi. org/10.1080/17565529.2014.953904

Nawrotzki, R. J., and J. DeWaard. 2018. Putting trapped populations into place: climate change and inter-district migration flows in Zambia. Regional Environmental Change 18:533-546. https://doi.org/10.1007/s10113-017-1224-3

Nicholls, R. J., C. W. Hutton, A. N. Lázár, W. N. Adger, A. Allan, P. G. Whitehead, J. Wolf, M. Rahman, M. Salehin, S. E. Hanson, and A. Payo. 2018. An integrated approach providing scientific and policy-relevant insights for south-east Bangladesh. Pages 49-69 in R. J. Nicholls, C. W. Hutton, W. N. Adger, S. E. Hanson, M. Rahman, and M. Salehin, editors. Ecosystem services for wellbeing in deltas: integrated assessment for policy analysis. Palgrave Macmillan, Cham, Switzerland. https://doi.org/10.1007/978-3-319-71093-8 3

Nielsen, J. Ø., and A. Reenberg. 2010. Cultural barriers to climate change adaptation: a case study from Northern Burkina Faso. Global Environmental Change 20:142-152. https://doi.org/10.1016/ j.gloenvcha.2009.10.002

Oliver-Smith, A., 2012. Debating environmental migration: society, nature and population displacement in climate change. Journal of International Development 24:1058-1070. https://doi. org/10.1002/jid.2887

Pascual, U., P. Balvanera, S. Díaz, G. Pataki, E. Roth, M. Stenseke, R. T. Watson, E. Başak Dessane, M. Islar, E. Kelemen, V. Maris, M. Quaas, S. M. Subramanian, H. Wittmer, A. Adlan, S. Ahn, Y. S. Al-Hafedh, E. Amankwah, S. T. Asah, P. Berry, A. Bilgin, S. J. Breslow, C. Bullock, D. Cáceres, H. Daly-Hassen, E. Figueroa, C. D. Golden, E. Gómez-Baggethun, D. GonzálezJiménez, J. Houdet, H. Keune, R. Kumar, K. Ma, P. H. May, A. Mead, P. O'Farrell, R. Pandit, W. Pengue, R. Pichis-Madruga, F. Popa, S. Preston, D. Pacheco-Balanza, H. Saarikoski, B. B. Strassburg, M. van den Belt, M., Verma, F. Wickson, and N. Yagi. 2017. Valuing nature's contributions to people: the IPBES approach. Current Opinion in Environmental Sustainability 26-27:7-16. https://doi.org/10.1016/j.cosust.2016.12.006

Paul, S. K., and J. K. Routray. 2011. Household response to cyclone and induced surge in coastal Bangladesh: coping strategies and explanatory variables. Natural Hazards 57:477-499. https://doi.org/10.1007/s11069-010-9631-5

Penning-Rowsell, E. C., P. Sultana, and P. M. Thompson. 2013. The 'last resort'? Population movement in response to climaterelated hazards in Bangladesh. Environmental Science \& Policy 27:S44-S59. https://doi.org/10.1016/j.envsci.2012.03.009 
Piguet, E. 2013. From "primitive migration" to "climate refugees": the curious fate of the natural environment in migration studies. Annals of the Association of American Geographers 103:148-162. https://doi.org/10.1080/00045608.2012.696233

Quinn, T., F. Bousquet, C. Guerbois, E. Sougrati, and M. Tabutaud. 2018. The dynamic relationship between sense of place and risk perception in landscapes of mobility. Ecology and Society 23(2):39. https://doi.org/10.5751/ES-10004-230239

Rabbani, G., A. Rahman, and K. Mainuddin. 2013. Salinityinduced loss and damage to farming households in coastal Bangladesh. International Journal of Global Warming 5:400. https://doi.org/10.1504/IJGW.2013.057284

Renaud, F. G., O. Dun, K. Warner, and J. Bogardi. 2011. A decision framework for environmentally induced migration. International Migration 49:e5-e29. https://doi.org/10.1111/ j.1468-2435.2010.00678.x

Rosell, S., and B. Holmer. 2007. Rainfall change and its implications for belg harvest in South Wollo, Ethiopia. Geografiska Annaler: Series A, Physical Geography 89:287-299. https://doi.org/10.1111/j.1468-0459.2007.00327.x

Roy, K., A. K. Gain, B. Mallick, and J. Vogt. 2017. Social, hydroecological and climatic change in the southwest coastal region of Bangladesh. Regional Environmental Change 17:1895-1906. https://doi.org/10.1007/s10113-017-1158-9

Saha, S. K. 2017. Cyclone Aila, livelihood stress, and migration: empirical evidence from coastal Bangladesh. Disasters 41:505-526. https://doi.org/10.1111/disa.12214

Schröter, M., E. H. van der Zanden, A. P. E. van Oudenhoven, R. P. Remme, H. M. Serna-Chavez, R. S. de Groot, and P. Opdam. 2014. Ecosystem services as a contested concept: a synthesis of critique and counter-arguments. Conservation Letters 7:514-523. https://doi.org/10.1111/conl.12091

Speare, A. 1974. Residential satisfaction as an intervening variable in residential mobility. Demography 11:173-188. https://doi. org/10.2307/2060556

Stedman, R. C. 1999. Sense of place as an indicator of community sustainability. Forestry Chronicle 75:765-770. https://doi. org/10.5558/tfc $75765-5$

Tebboth, M. G. L., D. Conway, and W. N. Adger. 2019. Mobility endowment and entitlements mediate resilience in rural livelihood systems. Global Environmental Change 54:172-183. https://doi. org/10.1016/j.gloenvcha.2018.12.002

Thompson, M. 2017. Migration decision-making: a geographical imaginations approach. Area 49:77-84. https://doi.org/10.1111/ area. 12292

Weldegebriel, Z. B., and M. Prowse. 2017. Climate variability and livelihood diversification in northern Ethiopia: a case study of Lasta and Beyeda districts. Geographical Journal 183:84-96. https://doi.org/10.1111/geoj.12178

Wolpert, J. 1965. Behavioral aspects of the decision to migrate. Papers in Regional Science 15:159-169. https://doi.org/10.1111/ j.1435-5597.1965.tb01320.x
Wondimagegnhu, B. A., and M. E. Zeleke. 2017. Determinants of rural out-migration in Habru District of northeast Ethiopia. International Journal of Population Research 2017:4691723. https://doi.org/10.1155/2017/4691723

Zickgraf. C. 2018. Immobility. Chapter 5 in R. McLeman and F. Gemenne, editors. Routledge handbook of environmental displacement and migration. Routledge, London, UK. https://doi. org/10.4324/9781315638843 


\begin{tabular}{|c|c|}
\hline Framework element & Definition/ operationalization \\
\hline Material NCP & $\begin{array}{l}\text { "substances, objects, or other material elements from nature that } \\
\text { directly sustain people's physical existence and material assets" (Díaz } \\
\text { et al. 2018:271) } \\
\text { - } \quad \text { Energy } \\
\text { - } \text { Food and feed } \\
\text { - } \text { Material, companionship and labor } \\
\text { - } \text { Medicinal, biochemical and genetic resources } \\
\text { - } \text { Maintenance of options }\end{array}$ \\
\hline Regulating NCP & $\begin{array}{l}\text { "functional and structural aspects of organisms and ecosystems that } \\
\text { modify environmental conditions experienced by people and/or } \\
\text { regulate the generation of material and nonmaterial contributions" } \\
\text { (Díaz et al. 2018:271) } \\
\text { - } \text { Habitat creation and maintenance } \\
\text { - } \quad \text { Pollination and dispersal of seeds and other propagules } \\
\text { - } \quad \text { Regulation of air quality } \\
\text { - } \quad \text { Regulation of climate } \\
\text { - Regulation of ocean acidification } \\
\text { - } \quad \text { Regulation of freshwater quantity, location and timing } \\
\text { - Regulation of freshwater and coastal water quality } \\
\text { - } \quad \text { Formation, protection and decontamination of soils and } \\
\text { - } \text { sediments } \\
\text { - Regulation of hazards and extreme events } \\
\text { - Regulation of detrimental organisms and biological processes }\end{array}$ \\
\hline Nonmaterial NCP & $\begin{array}{l}\text { "nature's effects on subjective and psychological aspects } \\
\text { underpinning people's quality of life, both individually and } \\
\text { collectively" (Díaz et al. 2018:271) } \\
\text { - } \quad \text { Learning and inspiration } \\
\text { - } \quad \text { Physical and psychological experiences } \\
\text { - } \quad \text { Supporting identities } \\
\text { - } \quad \text { Maintenance of options }\end{array}$ \\
\hline Migration need & $\begin{array}{l}\text { Resulting from a person's vulnerability (composed of risk exposure, } \\
\text { sensitivity and adaptive capacity (Adger 2006)) }\end{array}$ \\
\hline Migration ability & $\begin{array}{l}\text { A person's capacity to leave based on individual characteristics and } \\
\text { resources }\end{array}$ \\
\hline Migration aspirations & $\begin{array}{l}\text { A person's motivation to leave based on risk perception, self-efficacy } \\
\text { and place attachment }\end{array}$ \\
\hline Indicators & $\begin{array}{l}\text { Specific factors that allow conclusions on migration need, ability or } \\
\text { aspiration and can be directly linked with NCP, e.g. health status, } \\
\text { agricultural income, food and drinking water availability }\end{array}$ \\
\hline Moderators & $\begin{array}{l}\text { Specific factors that mediate the relationship between NCP and } \\
\text { migration need, ability and aspiration but are not directly linked to } \\
\text { NCP, e.g. gender roles, humanitarian aid, social networks }\end{array}$ \\
\hline
\end{tabular}

